\title{
Facts and Fallacies on Teamwork between School Administrators and Teachers in Secondary Schools in Mutasa District of Manicaland Province, Zimbabwe
}

\author{
Gombakomba, J. ${ }^{1}$, Oyedele, V. ${ }^{2}$, Chikwature W. ${ }^{3}$, Oyedele O. ${ }^{4}$ \\ ${ }^{1}$ Hartzell High School, Box 7024 Mutare \\ ${ }^{2}$ Africa University, P.O. Box 1320, Mutare, Zimbabwe \\ ${ }^{3}$ Mutare Polytechnic, Research Department, P.O. Box 640, Mutare, Zimbabwe \\ ${ }^{4}$ Namibia University of Science and Technology, Department of Mathematics and Statistics, Windhoek, Namibia
}

\begin{abstract}
Teamwork between teachers and school administrators is of paramount importance for the achievement of organizational goals as a school. This quantitative research examined the factors affecting teamwork between school administrators and teachers. The study population was a purposeful sample of 33 respondents comprising of 28 teachers and 5 school administrators in three secondary schools in one district. Focus Group Discussions were used to elicit the views of the teachers. The researcher used semi-structured interviews to collect data from the school administrators. Participant observations were utilized to consolidate findings from the focus group discussions and semistructured interviews. The study established that lack of teamwork results from gossiping, jealous, poor communication, mistrust, lack of respect, egocentrism, policies which are not user friendly and lack of transparency. This lack of teamwork was also discovered to bring challenges like witch hunting, hatred, and lack of cooperation, student indiscipline, and jeopardization of school programs, frustration, and demotivation of teachers, disgruntlements, and delay in implementation of policies and spreading of malicious gossip. Recommendations from this research were that staff development workshops on teamwork be held for teachers and school administrators, a two way communication channel between teachers and school administrators be embraced and truth and reconciliation forums for the two parties concerned be created. Policy makers were recommended to review their policies and adopt user-friendly ones which cultivate teamwork between teachers and school administrators.
\end{abstract}

Keywords-Factors, Teamwork, School Administrators, Teachers, Secondary Schools.

\section{INTRODUCTION}

Teamwork between teachers and school administrators forms the backbone of achievement of organizational goals at any school. Lack of teamwork can lead to the inefficient pursuit of organizational goals. Barriers to effective teamwork in the school can be created when administrators and teachers do not work together well and when they have major differences in their attitude towards school concerns among them. Arcaro in Coleman and Glover (2010:103) argues that "... teams need to be aware of the constraints inhibiting or fostering their progress" The constraints that impede teamwork between teachers and school administrators range from economic, cultural, political, personal and structural context within which the team is to develop.

Even Lunenburg and Ornstein (2012:8) in the human relations approach say "Communication, power, influence, authority, motivation and manipulation are all important relationships within an organization, especially between superior and subordinate." It is not surprising at all to see teachers or administrators being selfish enough to do things on their own, thereby overloading themselves with responsibilities, becoming ineffective and even eventually ill.

It is quite common that a group of people brought together to form a team like teachers and the school administrators do not really get along. This usually results in the failure to achieve organizational goals. When the teachers in a school fail to work together as a team with the school 
administrators, the effectiveness of the whole organization suffers. Teamwork between teachers and school administrators assembles their skills, experiences and insights to achieve a common purpose. Thus, it is a necessity in a school organization because Williams (2011) believes that quality of products offered by an organization improves when school administrators and teachers are given an incentive to work together and the authority to make improvements and solve problems. In the school setup, teamwork results in students producing good results.

According to McGregor's Theory $\mathrm{X}$ in Sinha (2008), managers believe that human beings have to be forced to make them work. This assumption by school administrators about teachers inhibits teamwork between them yet from Cohen's (2007) view, teamwork "Engenders enthusiasm, excitement for the work and the future." On the other hand, theory Y according to Sinha (2008:394) "... is based on the assumption that human beings have an internal disposition to perform their best." This makes teamwork between teachers and the school administrators quite beneficial because in successful leadership, administrators cannot do things on their own.

In teamwork between teachers and school administrators, it is the administrators' basic task is to make each teacher believe that he or she is a useful and an important part of the team.

Active participation by teachers on some decisions helps to build a team with the school administrators. This results in greater mutual understanding between the two parties.

One major cause of lack of teamwork between teachers and school administrators is that many varied aspects in a school setup, especially those aspects closely pertaining to work satisfaction, tend to be influenced by leadership behavior. "This might not go down well with the teachers. From this perspective, McGregor's Theory $\mathrm{X}$ assumption in Sinha (2008) that people are indolent in nature becomes a reality to the administrators. That is why they can at times set certain standards for teachers because they feel they need a push to do their work.

Motivation also plays an important role in promoting teamwork. That is why Lunenburg and Ornstein (2012:8) noted with concern in one of the human relations approach's assumption that "An individual's perceptions, beliefs, motivations, cognition, responses to frustration, values and similar factors may affect behavior in the work setting." Thus teamwork between teachers and school administrators can be adversely affected if teachers lack motivation.

Existing literature has tried to highlight the importance of teamwork in schools but still, there is a gap that needs to be closed on the factors affecting teamwork between teachers and school administrators. Pitsoe (2014) maintains that school administrators and teachers work in isolation and try to accomplish tasks alone hence the responsibility for implementing new ideas falls on individuals. As such, Mutasa District cannot be exceptional. This lack of teamwork has prompted the researcher to investigate the factors affecting teamwork between teachers and school administrators. The study therefore is aimed at unearthing those problems hindering teamwork between teachers and school administrators in three schools in Mutasa District, Manicaland, Zimbabwe. Even though education officials in Mutasa District have often highlighted the benefits of teamwork between teachers and school administrators during workshops; many schools in the district are characterized by divisions between the teachers and school administrators generally. Some school heads go as far as exercising dividend rule. This present situation raises concern worldwide but is not yet beyond control. Effective measures encourage teamwork between teachers and school administrators.

Lack of teamwork between teachers and school administrators impedes the achievement of organizational goals. It can also result in cases of indiscipline in the students' body. This in turn affects their academic performance which is the core business of an educational institution. Thus, it is of paramount importance to cultivate a team spirit between teachers and school administrators. No known researcher has seriously examined the factors influencing lack of teamwork between the teaching staff and school administrators. It is against this background that prompted the researcher to explore factors affecting teamwork between teachers and school administrators in Mutasa District, Manicaland Province, Zimbabwe, with the view of coming up with possible mitigations to the problems . This research sought to answer the following questions:

1. What are the characteristics of teamwork between teachers and school administrators in secondary schools in Mutasa District?

2. What are the benefits of teamwork between teachers and school administrators in Mutasa District, Manicaland, Zimbabwe?

3. Which are the factors inhibiting teamwork between teachers and the school administrators in Mutasa District, Manicaland, Zimbabwe?

4. Which are the effects of lack of teamwork between teachers and school administrators in Mutasa District, Manicaland, Zimbabwe? 
5. How can the problem of lack of teamwork between school administrators and teachers be solved in Mutasa District?

\section{MATERIALS AND METHODS Research Design}

The researcher used a qualitative research paradigm so that teachers and school administrators' experiences and perspectives in relation to teamwork can be examined and understood since qualitative research elicits verbal or visual data according to Oyedele (2011). The research was descriptive in nature as it will provide for an in-depth understanding of a situation and its contextual meaning for those involved (Creswell, 2008). This research design was used because it focuses on phenomena that we are aware of, but do not deeply understand primary sources, drawing from professional experience on factors affecting teamwork between teachers and school administrators rather than assumptions on the issue. It also enabled the researcher to interpret language or text through conduct in interviews.

\section{Population and Sampling}

The target population consisted of all secondary schools in Mutasa District. Teachers, senior teachers, school heads and their deputies participated in the selected schools because they were the concerned group for the study.

The sample consisted of three secondary schools from Mutasa District. From these schools, seventeen females and sixteen male respondents were selected to participate in this study. This process resulted in thirty three respondents of which twenty-eight were teachers and five school administrators.

The researcher used stratified sampling to group the school administrators and teachers separately to capture perceptions and responses from both sub-groups of teachers and school administrators involved in this study so that comparisons could be facilitated.

Purposive sampling technique was used to select who among the school administrators and teachers could be the respondents because the researcher is aware of the appropriate characteristics required of the sample respondents, which would satisfy the specific information needed.

\section{Data Collection Instruments}

\section{Focus Group Interviews}

These were used to get information from teachers because they increase reliability of the study since they verify findings.

Another strength of this instrument according to Ary, Jacobs and Sorensen (2010:439) is the "Researcher gains insight into how the participants are thinking and why they are thinking as they do." By engaging teachers in focus group discussion the researcher managed to capture teachers' perceptions which they deliberated on freely.

\section{Semi-structured Interviews.}

The researcher got firsthand information and school administrators' thoughts and feelings. Also, new ideas developed from the participants' answers during the interviews. According to Ary et al (2010) semi-structured interviews allow immediate follow up and clarification of participants' responses. These one on one interviews enabled the researcher to capture school administrators' gestures and expressions on teamwork. The researcher equally linked these with observations.

\section{Observations}

These established certain characters and behaviors of the teachers and school administrators. Ary (2010:431) highlights that observation "Allows the researcher to determine whether what is said actually matches actions or may illuminate subtleties that may be outside the consciousness of the person or that the person cannot articulate." Through observing teachers and school administrators at work, the researcher managed to capture natural events as they unfolded to assess whether teamwork between teachers and school administrators existed.

The interview participants were briefed on the interview protocol in advance of the interview. The interviews all took place in the respondents' offices and lasted for not more than thirty minutes. These were digitally audio recorded and then transcribed. The transcriptions were coded and used to create individual summaries.

The focus group discussions took place in classrooms of the respondents' choice. They lasted for not more than an hour and the researcher first highlighted to the participants the purpose, context and rules of the discussion. These focus group discussions were also recorded and transcribed. All participants for the semi-structured interviews and focus group discussions were appreciated for the data collection. The researcher also observed teachers and school administrators at work, in staff meetings, during break times and assemblies. Observation checklists were used in observing these activities. The researcher tried not to temper with the natural environment of the schools. She spent time with the participants and recorded natural events as they unfolded hence invasion of participants' privacy was inevitable.

Descriptive approach was used to analyze the collected data and explain the results. The researcher coded the focus 
group discussions and interviews she recorded. These were all analyzed soon after they were carried out to avoid piling up of work. There was comparison and integration of themes and concept. Common ideas from both interviews and discussions were categorized. The use of comparative methods like interviews and focus group discussions helped the researcher to cross validate the findings. The observations were used to consolidate findings from interviews and discussions. The researcher coded and then compared the observations from the three secondary schools.

Participation in interviews and focus group discussions was voluntary and anonymous. All precautions were taken by the researcher to ensure the confidentiality of the participants. The researcher assured all participants of the ethical treatment through their voluntary consent to participate in the interviews and focus group discussions. There was no deception involved in the collection of data, its analysis and reporting. Permission to observe the participants at work was granted by the school heads. Since participation by respondents was confidential and voluntary, there were no possible risks involved.

\section{RESULT AND DISCUSSION}

The five research questions generated for this research were presented using emerging themes as follows

Characteristics of Teamwork between Teachers and School Administrators in Mutasa District Secondary Schools.

Data collected from focus group discussions, semistructured interviews and observations was used to provide findings to the objectives. Question 1 of the focus group discussions asked teachers if they thought there was teamwork between them and school administrators, stating their reasons. The researcher felt that the teachers could provide reliable information on the existence of teamwork between teachers and school administrators. There were mixed feelings in participants in School A on whether they thought teamwork existed in their school. The majority of them denied the fact that teamwork was visible in the school. Quite a number of them stated there was partial teamwork whilst only a handful acknowledged its existence. Respondent R7 explicitly stated that

At this school, teachers are not part of important decision making but are just given information. Some key issues come to teachers as mere announcements.

According to the respondents who denied the existence of teamwork between teachers and school administrators, some of the common reasons they stated were lack of teacher motivation, school administrators lack the knowhow to initiate teamwork, lack of communication from school administrators, a lot of gossiping that goes around, administrators being very secretive and having dictatorial tendencies.

According to respondent R3

There is too much delegation of duties by the school administrators whilst they assume the role of spectators.

Respondents R1 said teamwork between teachers and school administrators did not exist because

School administrators are given a lot of benefits hence teachers sabotage everything for them to do.

Another respondents R4 was of the opinion that there was no teamwork between teachers and school administrators because

Administrators craft policies in the school to their advantage or even to fix teachers.

From the above responses (Dale 2006:117) is proven right when he says "Administrators set the tone the tenor and the climate for how the school operates as a team or not as a team." Thus the school administrators are the major stakeholders in teamwork between teachers and school administrators. It also unquestionable that varying leadership styles also constitute teamwork. Also, oneness is another important aspect in teamwork. The respondents who said there was partial teamwork at their school cited reasons such as divisions and mistrust between teachers and school administrators, teachers input is sometimes not implemented and the administrators have no quality targets hence their targets vary with teachers'.

Respondent $\mathrm{R} 2$ explained that

Teachers are a little relaxed on student discipline while administrators are somehow responsible. Students actually show this by reacting differently to both teachers and administrators when they are found breaking rules and regulations. They become afraid in front of administrators. On the contrary, they relax when found on the wrong side of rules by teachers.

Another respondents R5 said partial teamwork in their school was as a result of school administrators who think they know it all until problems arise and they start consulting teachers.

From the above reasons, it is quite clear that some of the shortfalls at the school are as a result of lack of wholesome teamwork. This calls for total commitment from both parties for the school to be more efficient. The results show that teachers and school administrators tend to relax at the expense of teamwork. 
Respondents R9 and R1 who said there was teamwork in their school said it was because teachers and school administrators share meals together, discuss school issues and solve problems together, resources were available, both teachers and school administrators work towards discipline in the school and there is consistent communication between the 2 parties involved.

Respondent R13 said

The fact that we are consulted as teachers by school administrators on most issues and our opinions are considered shows that there is teamwork in our school. Besides that, administrators unanimously make decisions with us.

It is evident from the responses that teamwork between teachers and school administrators results in the efficiency of the school as an organization.

The researcher also gathered this view from respondent R30 on how teachers and school administrators contribute towards teamwork

Teachers and school administrators work together on change and change management, enhancement of school programs and promotion of school activities for the school's achievement of goals.

Common responses from the participants about how teachers and school administrators contribute towards teamwork included focusing towards development of the school, adherence to school timetable, calendar of events and provision of circulars.

Respondent R31 expressed that;

As school administrators, we try to work hand in glove with our teachers therefore bidirectional relationships exist.

These results show that teamwork comprises of shared vision, goals and commitment. Some of the common responses that were brought out by the participants on how school administrators motivate teachers to embrace teamwork were creating room for open door policies, embracing grievances procedures, open flows of information and staff development.

Respondent R29 said that as school administrators, one way they use to motivate teachers to engage in teamwork is by applauding teachers' strengths and working towards improving weak areas.

The researcher observed that most of the teachers were at work during the period of investigation. However at School A, some teachers had a tendency of leaving the school when they had some personal matters to attend to and then return later. This encourages indiscipline among students because sometimes they are left unattended.
All the three schools held briefings between teachers and school administrators after assemblies where they would discuss matters which required attention. At School A, the researcher observed that there were even more briefings as well during break time as the teachers were having tea in the staff room. At School B, circulars would go around to inform teachers off any sudden developments.

From the observations made by the researcher at School A, teachers always had tea and lunch together but certain school administrators never had the opportunity to join others. Both teachers and school administrators worked together on selection of prefects but the school administrators went on to select the heads of the prefects on their own without the input of the teachers.

All teachers and administrators at School B had tea together at break time. The school administrators also worked together with teachers to ensure that schools were thoroughly cleaned by students before school closure. At School C, teachers and some administrative personnel always had tea together with teachers whilst they socialized. They also worked together in planning to host a meeting which was to be held at their school, with the administrators' delegating duties and some of the teachers volunteering. This creates solidarity and a sense of belonging between the teachers and school administrators.

During one of the tea breaks, the researcher observed one administrators who brought cakes and scones for free for all the teaching staff to enjoy at break time. At School B, one administrator seemed to be very unfriendly with his subordinates. This came as no surprise at all since he had been very hostile to the researcher before when he was approached for an interview. Two of the administrators at School C were very sociable. Teachers felt very free to talk, laugh and joke with them in a respectful manner. School administrators should show that they are also human beings. If they can criticize teachers for judging them unfairly, then they must also socialize. If they are anti-socialists it will not be an easy task for the teachers to work as a team with them.

Furthermore, the researcher observed that the school administrators at School A consulted teachers during meetings and briefings on matters of their choice. On other matters, they would already have laid down decisions and this would trigger disgruntlements among the teachers. The administrators at School B would bring laid down suggestions but give floor to rest of the teaching staff to finalize. Administrators at School $\mathrm{C}$ consulted teachers on the way forward pertaining to some issues. The above information shows that there is consultation of some sort 
from teachers, even if in some cases it might not be always. Consulting teachers for formality's sake at times results in their passive resistance.

Benefits of Teamwork between Teachers and School Administrators in Mutasa District

Responses from focus group discussions and semistructured interviews were used to meet the objective.

During the focus group discussions, all the respondents acknowledged the importance of teamwork between teachers and school administrators. The following were some of the benefits cited by the respondents.

\section{Improvement of Academic Standards}

Several respondents noted that when teachers work with school administrators together as a team, students tend to attain good results. This is because team working brings commitment to both teachers and administrators in their work. When they are committed to do their jobs diligently, they become efficient and students attain good results.

\section{Improved Relationships}

Respondent R23 noted that

When teamwork exists between school administrators and teachers, relationships between them become better and everyone has a sense of belonging. Administrators can provide teachers with resources and teachers in turn give information of the state of the school to the administrators.

\section{Solutions to Problems}

This was a common benefit that was raised by Respondents R4, R17, R23 and R26. Their argument was that if a problem is shared, it is half solved. Thus according to them by team working, teachers and school administrators can come up with possible solutions that they might not think of on their own.

\section{Reduced Duplication of Efforts}

Respondent R6 said that

When teachers and school administrators engage in teamwork, this avoids duplication of efforts because responsibilities will not be awaiting a few individuals.

\section{Setting the Tone and Traditions of the School}

According to Respondents R11 and R15, if school administrators work together with teachers, they build a name for their school in the long run. This teamwork builds a good reputation for schools because of the multiple effort of teachers and school administrators.

\section{Motivating Towards Goal Accomplishment}

Respondent R8 contended that

If there is teamwork between teachers and school administrators, teachers are motivated towards accomplishing their goals and they execute their duties without reservations.
The above responses show that teamwork between teachers and school administrators is of paramount importance. These findings clearly redefined the benefits of teamwork between teachers and school administrators. It is also important to note that even though teachers may not at times engage in teamwork with school administrators, they are very much aware of its benefits. In addition, lack of teamwork with school administrators implies that they will be depriving the school as an organization.

This is consistent with observations made by Williams (2011) in view of teamwork's importance, said it leads to increased job satisfaction in most cases.

When asked their opinions on teamwork between teachers and school administrators in their school, respondents R29 had this to say;

There is a high level of cooperation between the two which has been the norm of the day.

According to Respondent R30

There is partial teamwork where part of the teachers are in sync with the administrators whilst part of them are not.

These findings show that the two administrators in School A have contradictory perceptions on the existence of teamwork between teachers and school administrators.

In School B, Respondent R31 said teamwork between teachers and school administrators promotes good communication in their school. He further said it builds good relationships and trust among staff members. From these findings, it shows that teamwork has yielded positive results in the school.

The respondents at School $\mathrm{C}$ said that teamwork between teachers and school administrators has led to peaceful coexistence, unity of purpose, smooth running of the school and coordination of school programs and activities.

These findings also show that teamwork between teachers and school administrators is beneficial to school organizations.

3. Inhabitants of Teamwork between Teachers and School Administrators in Mutasa District

The majority of the teachers in the 3 secondary schools said they were not motivated to engage in teamwork with school administrators.

Respondent R12 gave the following reason;

As teachers, we feel we are not part of the group because most suggestions from the teaching staff are not taken aboard.

From respondent R10

When we engage in teamwork with school administrators, it is not because we feel motivated to do so. No madam! We will be just complying as a form of ministerial expectations.

Page | 36 
Also, we do our work for the love of it. The despot administrators thwart our efforts to engage in teamwork!

The other participant also cited unfairness on benefits between them and school administrators as a common hindrance.

Respondent R26, also expressed that

Teachers do more work and yet the administrators award themselves hefty allowances whilst teachers get little or none. Above all, our children are send back home by these administrators for non-payment of fees. And you think we can feel motivated together work such selfish and greedy people!

Another respondent, R14 was of the opinion that Teachers cannot support a system which they are not fully informed on or which involuntarily excludes them. We, as teachers, are uncertain of what the administrators think of us.

Respondent R20 also highlighted that

There is no conducive working atmosphere for team working with the administrators. Teachers are blamed for everything that goes wrong in the school. If there is student unrest, administrators label teachers for inciting them. As a result we are reluctant to be involved in teamwork.

From the above given responses it is true that "When school climates become cold and teachers perceive principals as suspicious and negative, a reformation has to occur before teachers are willing to modify instruction." Edgerson et al (2006:3) it is of paramount importance for school administrators to try their best to avoid creating a cold climate for teachers. Trust is therefore needed for both parties to collaborate as clearly stated by Robbins et al (2009) that teamwork is characterized by high mutual trust. Teachers blamed both teachers and school administrators for lack of teamwork. Common reasons for the blame on administrators included they do not engage teachers, they do not respond to teachers' problems and they override committees' assigned tasks.

One respondent, R1 blamed the school head because

He is the member in charge. The one who owns the piper sets the tune. So if there is lack of teamwork, it is because of the school head.

Respondents R6 from the same school also echoed this sentiment.

The school head is the weak link who is very selfish and allows his subordinates in the administration to rot with him and fail to keep standards.

Another participant from the school, R2 also nailed the responsibility of lack of teamwork between teachers and school administrators on the school head because according to her
He uses military style- iron grip and hardly considers what subordinates say resulting in the teachers just watching as things go bad in the school.

Respondents R16 said both teachers and school administrators should shoulder the blame for lack of teamwork because

They both sometimes do not participate when teamwork is needed. Some administrators impose on teachers whilst teachers can also be stubborn.

These findings show that both teachers and school administrators have a role to play towards the establishment of teamwork. Equally important is the fact that the school administrators are the key players in the establishment of teamwork. According to Dale (2006:117) "Administrators set the tone, the tenor and the climate for how the school operates as a team or not as a team." Teamwork will only be established when these administrators work hand in hand with teachers because they do not know everything. That is why Rickets and Rickets (2011:78) advised that school administrators "....must assemble a team and assign tasks that play to members strength."

Most of the participants highlighted lack of trust, respect and transparency, ingratitude, gossips, full of 'I know', fear of the unknown, centralization of decisions and differences in personalities as owing to lack of teamwork between teachers and school administrators.

According to respondents R5

Status quo has hindered teamwork between teachers and school administrators. Those who are promoted to be in the school administration do not want to be associated with other teachers and vice versa.

Participant R13 also noted with concern that

Jealous between the two groups also constitutes to lack of teamwork. Other administrators cannot accept the academic gap between them and some of their subordinates. They feel threatened by teachers with higher academic qualifications than them. The moment that these teachers make valuable contributions zvinonzi aakuda kuonererwa.

The above statement implies that when teachers with higher academic qualifications make some contributions, the school administrators say that they want to show off.

Other common hindrances that the teachers outlined were poor leadership qualities, double standards by both teachers and administrators, autocracy, laziness, shortage of resources and sabotage by teachers.

From the above findings, it is quite clear that if school administrators wish to establish teamwork with teachers, they cannot do away with trustworthiness, consultation,

Page | 37 
respect, justice, sincerity, commitment, communication, transparency, equity, staff development, varied leadership styles and flexibility among other attributes. Also, teachers need to be respectful, committed, and confident, work hard, and stop being frightened by the unknown and spreading harmful gossip. If both teachers and school administrators work towards curbing the above mentioned hindrances, then teamwork is guaranteed between them. When asked whether teachers and school administrators were interested in teamwork, respondents at School A who felt that teachers were interested whilst administrators were not gave the following explanations:

Respondents R8;

Teachers want to work together with the administrators to reduce indiscipline in the school and hence achieve organizational goals. The administrators are not result oriented hence they do not even care about taking part in maintaining discipline. They believe teachers must work whilst they do nothing and do as they wish in the school.

Respondent R4 said;

The school head is interested but the administrative personnel are not because they feel threatened and do not want the head to appreciate and recognize effective and potential leaders within the teachers.

Respondent R9 thinks that

School administrators feel that the positive developments of teamwork challenge their weaknesses.

Participant R1 was of the opinion that school administrators have always discussed issues in bad faith hence teachers feel cheated and used. The participant further stated that teamwork consolidates the power that the administrators think they have so they become uninterested.

Respondents at the same school who think both teachers and school administrators were interested echoed the following sentiments.

Respondent R2 said

Open forums have been initiated at times but the problems come in embracing different opinions.

At School B, the respondents had varied perceptions on whether they thought teachers and school administrators were interested in teamwork. Participant R18 said that teachers are interested so that they do not feel out-casted whilst administrators were not because they want power and authority vested in them.

Of the two respondents who think only teachers are interested, R27 said that teachers are the ones who usually air out the need for teamwork at their school. Participant 20 said
The administrators are just like puppets who can hardly make decisions in the absence of the school head.

In response to whether school administrators find solutions to factors inhibiting teamwork between teachers and school administrators respondent $\mathrm{R} 27$ said

The administrators are the root factors inhibiting teamwork. They think having conflicts with teachers means one is a good administrator.

Participant R14 expressed the following feelings towards the question;

Administrators window dress both in their spoken words and on paper when addressing formation of committees but when they are with teachers they need one on one.

In support of this view, respondents R19 said

The school administrators put teachers in committees but they prefer individualism, or splits and chaos within the committees as they rule by divide and rule principle. From the responses of all the participants in the three different schools, it can be deduced that both teachers and school administrators are aware and interested in teamwork but their selfish needs tend to override this interest. No wonder why Naidu et al (2008) highlighted that the centrality of certain individuals can, however act as a hindrance to teamwork.

When asked if satisfied with what school administrators offer towards teamwork with teachers, respondent R3 said

The school administrators look down upon teachers especially when it comes to financial motivation. There is a wide gap in terms of incentivizing teachers and school administrators.

From participant R10's view,

There is a lot of tongue in-check type of attitude in which the administrators do not seem to know the value of teachers and so they offer very little by way of encouraging work.

Respondent R5 was of the opinion that

Both groups remain insincere because what they say is not practiced as per the agreements. Usually, administrators provide anything towards teamwork after being arm twisted.

According to participants R15

The school has a great potential to become one of the best schools in academic performance but the administrators are not doing much to improve teamwork because they fear that may translate into improved benefits for teachers. Izvozvo ndizvo zvavasingade manje. This means that one thing that the administrators do not like for certain is anything that benefits teachers.

Participants R28 expressed that 
As long as the administrators get something that the teachers are not getting, then teamwork is a dream in this school. Involving everybody means involving everybody pamari nebasa"

The respondent implied that involving everyone means involving everybody in both monetary benefits and work.

Other participants agreed that divisions between teachers and school administrators always manifest because of waitand-see attitude in teachers as well as injustice by administrators.

According to Respondents R22

If teachers contribute better than the administrators zvinonzi vakangwarisa - vaakuda kupidigura chikoro."

This means if teachers make a better contribution than administrators they are considered as getting out of handrebels.

At School C most respondents said they were not satisfied because the administrators were dictatorial. Another respondent said she was also dissatisfied because there was still tension between the two parties. Two of the participants said they were satisfied because the administrators always update them with their plans.

Common impediments that the school administrators raised that contribute towards teamwork are mistrust between the two, education policies which are not user friendly, unavailability of incentives to appreciate teachers, egocentrism, democracy and varied levels of education.

As respondent R31 blankly pointed out

Lack of communication between teachers and school administrators as well as limited or no staff development hinders teamwork.

The overall responses show that once trust lack between teachers and administrators, teamwork is barred. It is of particular interest that even though teachers have raised concern on the lack of democracy as a barrier to the establishment of teamwork, one of the administrators sees it as a possible hindrance.

Observations made at School A reflect that the same teachers participated throughout the meetings. At School B, all the teachers seem to participate whilst at School C a few teachers were not actively involved during these meetings. This suggests that those teachers that usually do not participate may be engaging in passive resistance because surely they cannot have nothing to contribute all the time. That is why at times other administrators do not consult teachers and make some decisions on their own.

Compliance teachers on school administrators' orders was also observed to be varying in the three school. At School A, most of the teachers followed orders although some did not comply for example indicating student daily attendance, ensuring cleanliness in their classrooms and reporting students who did not submit their report books. Some teachers at School B also failed to meet deadlines laid down by the administrators as submitting marks at the end of the term. The administrators at School $\mathrm{C}$ had to constantly give reminders to some teachers on orders they had to follow. Those teachers who do not follow administrators' orders contribute to creating a rift with the administrators. This maybe because when administrators make a follow up, tension is brewed and relationships between the parties concerned become sour. In such cases, teamwork stands little or no chance to be created.

Observations made seemed to indicate that most of the school administrators at School A were usually punctual except one who was always late during the time that the participants were under observation. Also, not all teachers were punctual at the school. Quite a number of them would come to work after assembly. At School B, all the administrators were punctual although some teachers came to work late. This was the same scenario at School C. This results in lack of teamwork between teachers and school administrators because only a few staff members try to put things in place when their colleagues are not yet at work.

From the researcher's observations resources were readily available in School A. The researcher was lucky enough to witness the delivery of examination materials for end of year exams during her observation. At School B, the researcher observed that only the school availed resources that they could afford. Unavailability of some resources at School C was observed that is was not because they were beyond the reach of the school but the administrators had not just made an effort to buy them, for example chalks, brooms and strings to tie exam scripts.

\section{Effects of Lack of Teamwork between Teachers and School Administrators}

According to the participants from school A, their school has experienced gross student indiscipline, conflicts, victimization of teachers, stereotyping, lack of development, hatred and unfair distribution of resources because of lack of teamwork between teachers and school administrators.

Participants R6 clearly stated that

Because of lack of teamwork there is usually passive resistance by teachers. We usually refuse to contribute towards problem solving owing to the feeling that the administrators only want to use us when they are stranded.

Another respondent R9 also noted with concern that 
There is lack of initiative by teachers as ideas are constantly viewed as anti-administrative.

Respondents R2 also highlighted that lack of teamwork leads to

....the creation of unwanted gulf- a tall order in aligning the teachers and school administrators.

The challenges that have been met at School B include insubordination by teachers, low teacher morale, poor resource mobilization and low pass rate. At School C, pass rate decline, timetable clashes and lack of engagement and participation have arisen due to lack of teamwork between teachers and school administrators.

Pass rate decline, student indiscipline and limited development were common consequences of lack of teamwork between teachers and school administrators in all the 3 schools.

As an administrator, respondent R29 highlighted that their school had encountered delays in the implementation of policies and jeopardizing of school programs because of lack of teamwork. Respondent R30 said

Because of lack of teamwork, there has been witch hunting between teachers and school administrators. If anything goes wrong, the teachers seem to shift the blame to the school administrators. They always have their eyes wide open to see any wrong move that is made by their superiors. This in turn leads to backbiting of school administrators by the teachers.

According participant R31 at School B, hatred, gossip and frustration have been the fruits reaped because of lack of teamwork.

Respondent R32 said

There has been student uproars frequently which could have been avoided if teachers worked together with school administrators. Because of these student uproars, our school is so much under scrutiny and the media has publicized a bad reputation of our school.

According to respondent R33

Teachers and school administrators are disgruntled. Teachers think that the administrators are selfish, the school administrators believe teachers do not want to cooperate.

5. Establishment of Teamwork between Teachers and School Administrators

Respondents R25 suggested that

School administrators should emulate Jesus Christ who came to serve and not to be served.

The most common solutions that were suggested by R15, R2, R12, R20, and R26 were

a. Regular feedbacks by school administrators to teachers. b. Two way communication.

c. Administrators should lead by example in executing their duties.

d. Providing adequate resources for teachers.

e. Consultation of ideas from teachers.

f. Staff development workshops.

From the above suggestions, if both teachers and school administrators embark on putting them into practice, these can yield teamwork as a result. McFarlane (2014) observed that teamwork between teachers and school administrators begins with communication.

Respondent R12 gave the following opinion when she admitted administrators find solutions to factors inhibiting teamwork between teachers and school administrators.

In all meetings, as administrators, we emphasize working together.

Respondent R26 also said that the mere allocation of duties to all staff members is an effort to establish teamwork. When asked what could be done to cultivate or strengthen a team spirit between teachers and school administrators respondent R22 suggested Everyone must try to be committed to his/ her job. Once an individual is committed, they get to know the value of teamwork and will speak the same language of team working with other committee members.

Other commonly raised suggestions to cultivate teamwork by the administrators were openness, consultations, transparency, and building trust, implementation of statutes, staff development5 and good communication.

Participant R31 suggested that

Teachers and school administrators must develop respect for and upkeep of setup school systems and departments.

In agreement to this, respondent R33 said

The upkeep of national, district and visions nurtures teamwork between teachers and school administrators.

From the above findings it is interesting to note that the school administrators are also aware that in the process of cultivating teamwork with teachers, they also have a part to play. Together with the teachers, they have to build trust among them, discuss issues openly, and consult each other before making important decisions in the school.

\section{Discussions and Interpretation}

According to Pitsoe (2014) teachers and school administrators work in isolation, try to accomplish tasks alone hence the responsibility for implementing new ideas falls on individuals. These sentiments were in line with the current study where it was found that there was lack of teamwork between teachers and school administrators in

Page | 40 
Mutasa District even though both parties are quite aware that it is important in schools as organizations. This was a clear indication that there are factors that affect teamwork between teachers and school administrators.

The study also revealed that teachers mostly blamed the school administrators for lack of teamwork between them. The major reasons that were cited by the majority of the teachers were selfish motives by the school administrators, poor communication and status quo. Also, it was interesting to note that some of the teachers personally realized that they contributed to lack of teamwork by blame shifting, gossiping, lack of commitment and being jealous of their superiors.

It also became apparent from this research that teachers feel demotivated to engage in teamwork with administrators. From the findings, the key to teachers' motivation seems to be the school administrators.

According to this study both teachers and school administrators contribute to lack of teamwork. The main reason for this persistent attitude seems to be counter-action by parties concerned. As long as teachers continue to reiterate all the bad things they feel their school administrators are doing to them, and vice versa, no school will be headed towards team working in the district.

Furthermore, the findings revealed that both teachers and school administrators need to be aware of what hinders teamwork between them in their schools so that they can try to adjust. This adjustment on is part of cultivating team spirit within a school.

The study also showed that lack of teamwork between teachers and school administrators brings a lot of challenges in the school. These challenges do not only affect the two concerned parties but they also spill to the students. Apart from this, the researcher also revealed that lack of teamwork creates tension between teachers and school administrators. This implies that human relations are strained in the whole school as a result of lack of teamwork between the two groups.

From this research, the researcher discovered that it is very possible to establish teamwork between teachers and school administrators regardless of their varying personalities and opinions. Even Coleman and (Glover 2010:99) maintains that "....schools and colleges can be more effective if people understand team dynamics, how they can contribute to their full potential to their team and understand their leadership culture within which teams operate."

The findings also revealed that teachers are interested in teamwork but they think school administrators are not because they think this would bridge the gap of superiority with teachers. That is why Naidu et al (2008:108) observed that "....there is an increased potential for relationships that threaten to disable schools from carrying out their core business effectively." This shows that some administrators want the difference between subordinates and superior to be very evident in their schools. This attitude has turned out to hamper teamwork because at times, it is has resulted in unfairness.

It was also evident from this study that most of the school administrators do not attempt to find solutions to the problem of lack of teamwork between teachers and school administrators.

Most teachers were found to be dissatisfied what school administrator's offer towards teamwork. It seems as if as long as the school administrators do not fight for the recognition of their hard work even as subordinates, teachers will remain dissatisfied on what administrators offer towards teamwork.

The researcher also revealed that school administrators have yielded positive results in their schools when they engage in teamwork with teachers. This is in support of Williams (2011) who noted that the quality of products offered by an organization improves when superiors and subordinates are given an incentive to make improvements and solve problems together.

It was also evident that both teachers and school administrators possess some characteristics of teamwork like shared ideas, openness, goal-oriented, and two-way communication. The fact still remains that if teamwork is to be established in the district, both teachers and school administrators need to embrace all the characteristics of teamwork.

The researcher also found out that school administrators in the three schools try to motivate teachers to embrace teamwork through open door policy, applauding teachers' strengths and working towards improving weak areas and providing incentives.

The school administrators also laid some of the blame for impediments of teamwork on teachers apart from other forces that they have no control of like educational policies.

Several challenges have been met in the schools under study which also include massive indiscipline in students. Most of these challenges can be conquered if teamwork between school administrators is established.

The school administrators also raised constructive suggestions which when implemented can both cultivate and strengthen a team spirit with teachers. It was an interesting to note that the school administrators realized that they had an important role to play in establishing

Page | 41 
teamwork with teachers through transparency, consultations, building trust, providing resources for teachers and good communication among others.

The researchers also observed that not all teachers participated during meetings. Some do not contribute as a way of sabotage to administrators. Therefore teamwork becomes non-existent in such cases. In contrast, the researcher also noticed that school administrators sometimes consulted teachers for formality's sake when they had already made decisions on some issues and promise to "look further into the issues." This is a move that can also demotivate teachers from engaging in teamwork with the administrators. As a result, at times when consulted for ideas the teachers can practice passive resistance because they will be aware that they would have been consulted just for formality's sake.

The findings also revealed that there were some stubborn teachers who do not follow administrators' orders. Teachers inhibit teamwork with school administrators when they do not comply with their orders. Because administrators are their superiors, teachers need to do as they are told.

Since punctuality by both teachers and school administrators sets a good example for students, it is also an important aspect to consider in the establishment of teamwork. The researcher found out that quite a large number of the teachers came to work late but most of the administrators were punctual. This lateness also contributes to one of the challenges of lack of teamwork-indiscipline among the students. This is because if a few teachers are in the school with a large number of students, they cannot control them alone. Apart from that, these students are very observant. They also develop tendency of coming to school late just like their teachers. This then means a drop in their pass rate because important learning time is lost.

The study also showed that communication existed between the school administrators and teachers through briefings, meetings and circular. This needs to be commended as communication according to McFarlane (2014) said teamwork is the stepping stone for the establishment of teamwork between teachers and school administrators.

Routine sharing and joint work was prevalent in all schools. Whenever the teachers engaged in joint work with administrators things went on very well in the schools. Sharing meals together seemed to cultivate a spirit of oneness between the teachers and school administrators as they relaxed whilst socializing together.

The researcher also found out that teaching resources were not fully available to all teachers. When teachers are deprived of teaching resources, team working can be a problem.

It was also observed that not all administrative personnel led by example. If administrators do not want to associate with teachers because of their positions classes are created among the teaching staff. This also hinders teamwork.

\section{CONCLUSIONS}

Based on the key findings of the study, it can be concluded that to a greater extent, leadership styles determine the establishment of teamwork with teachers. Disparities in benefits and conditions of work has been seen to take schools back in terms of development. Major challenges that have been encountered because of lack of teamwork include gross students' indiscipline, low student pass rates, victimization of teachers, stereotyping and lack of development in schools.

A comprehensive collaboration approach is required in establishing teamwork between school administrators and teachers. Workshops on teamwork building should be attended by both teachers and school administrators. Clearly defined communication channels should be established in schools by both parties concerned. Also, regular meetings whose agenda is teachers' welfare should be regularly held. A conducive working environment can then be created which promotes the establishment of teamwork between teachers and school administrators.

\section{Implications}

With regards to factors affecting teamwork between school administrators and teachers in Mutasa District, the researcher feels that though administrators take the lead in schools, they are not reflecting on the role they are playing in trying to establish teamwork with teachers.

Teachers also do not realize that they must not always blame shift lack of teamwork on school administrators.

Both teachers and school administrators must realize that they have to play their part in a bid to establish teamwork with each other.

\section{Recommendations for School Administrators}

Based on the findings of the study, the researcher recommends that school administrators must arrange staff development workshops on team building on a regular basis. This can cultivate a team-spirit between the two parties. To curb disgruntlements from teachers, school administrators must also try to hold regular meetings to address the welfare of teachers and their grievances. The school administrators are also recommended to initiate open 
forums for decision making on major issues that affect the school. By so doing, ideas and solutions to problems can be shared between teachers and school administrators. It is also advisable for the school administrators to lead by example in executing their duties through commitment to their work. This can make teachers follow suite and establish a stepping stone for the formulation of teamwork.

The researcher also recommends that teachers be appreciated for their commitment and good work by school administrators. Also, school administrators must view teachers as their colleagues and team mates rather than subordinates. If they implement this, oneness becomes evitable. A clearly defined two way communication channel; that is a top down and bottom up must be embraced. School administrators are also encouraged to vary leadership styles depending on the situation. Differences in individuals must be considered by school administrators and they should also establish good rapport with teachers.

Another recommendation from the researcher is that school administrators should acknowledge that teachers are also above the prefects just like the administrators. This will make them feel important to the administrators. Continuous improvement of conditions of work for teachers and providing adequate resources for them to do their jobs diligently is also recommended by the researcher. If this happens, teamwork becomes easy to establish. School administrators must ensure that they establish truth and reconciliation forums for teachers and school administrators. The spread of malicious rumors can be stopped in the long run. The school administrators must also communicate goals and objectives of the school to teachers. Being transparent, trustworthy and respectful towards teachers creates room for the cultivation of teamwork between teachers and school administrators. Administrators must also terminate jealous attitudes towards subordinates who have better professional qualifications than them. Rather, they should make use of these teachers to the advantage of the creation of a strong team.

\section{Recommendations for Teachers}

The researcher recommends that all teachers must engage in openness rather than spreading malicious rumors among staff members. Effort must also be made by teachers to terminate jealous attitudes towards administrators for being their superiors. They should appreciate that they cannot all become school administrators and hope that one day they will also be elevated to become administrative personnel. The researcher also recommends that teachers consult school administrators and interact with them. By so doing, a feeling of belonging can be instilled in them. Also, teachers must participate and get involved in school activities. Teachers also need to respect administrators as well as trust in them because they are their superiors. It is also advisable for teachers to share ideas with school administrators as this will lead to efficiency in schools. Also important is for the teachers to be committed to their work as this will lighten the burden for school administrators.

\section{Recommendations for Policy Makers}

The researcher recommends that policy makers adopt userfriendly policies that cultivate teamwork between teachers and school administrators.

\section{REFERENCES}

[1] Ary D. Jacobs, L.C. Sorensen, C. (2010). Introduction to Research Education. 8th Edition. U.S.A: Cengage Learning.

[2] Cohen, E. (2007). Leadership without Borders. New Delhi: Wiley India (P) Ltd.

[3] Coleman, M. and Glover, D. (2010). Educational Leadership and Management. England: McGraw-Hill.

[4] Dale, J. (2006). Improving Teachers Retention by Building Teamwork. Images. Pearson assessments.

[5] Lunenburg, F.C and Ornstein, A.C. (2012). Educational Administration. 5th Edition. USA: Cengage Learning.

[6] McFarlane, O. (2014). Teacher Principle Relationship: the effect on student outcome. http://www.academia.edu/

[7] Naidu, A., Joubert, R., Mestry, R., Mosoge, J. and Ngcobo, T. (2008). Education Management and Leadership. South Africa: Oxford University Press.

[8] Oyedele, V.I. (2011). Research Methods. Windhoek: Zebra Publishing (Pty) Ltd.

[9] Pitsoe, V.J. (2014). How do School Management Teams Experience Teamwork? A case study in the Schools in Kamwenge District, Uganda. Mediterranean Journal of Social Sciences, 5(3): 69-86

[10] Sinha, J.B.P, (2008). Culture and Organizational Behavior. India: SAGE Publications.

[11] William, C. (2011). Principles of Management. USA: Cengage Learning. 